University of Nebraska - Lincoln

DigitalCommons@University of Nebraska - Lincoln

Faculty Publications, Department of Child, Youth, and Family Studies

Child, Youth, and Family Studies, Department of

2017

\title{
Examining the Role of Teacher Presence and Scaffolding in Preschoolers' Peer Interactions
}

Ibrahim H. Acar

Istanbul Medipol University, ihacar@medipol.edu.tr

Soo-Young Hong

University of Nebraska-Lincoln, shong5@unl.edu

Chaorong Wu

University of lowa

Follow this and additional works at: https://digitalcommons.unl.edu/famconfacpub

Part of the Developmental Psychology Commons, Family, Life Course, and Society Commons, Other Psychology Commons, and the Other Sociology Commons

Acar, Ibrahim H.; Hong, Soo-Young; and Wu, Chaorong, "Examining the Role of Teacher Presence and Scaffolding in Preschoolers' Peer Interactions" (2017). Faculty Publications, Department of Child, Youth, and Family Studies. 276.

https://digitalcommons.unl.edu/famconfacpub/276

This Article is brought to you for free and open access by the Child, Youth, and Family Studies, Department of at DigitalCommons@University of Nebraska - Lincoln. It has been accepted for inclusion in Faculty Publications, Department of Child, Youth, and Family Studies by an authorized administrator of DigitalCommons@University of Nebraska - Lincoln. 


\title{
Examining the Role of Teacher Presence and Scaffolding in Preschoolers' Peer Interactions
}

\author{
Ibrahim H. Acar, ${ }^{1}$ Soo-Young Hong, ${ }^{2}$ and ChaoRong $\mathrm{Wu}^{3}$
}

1. Department of Early Childhood Education, Istanbul Medipol University, Istanbul, Turkey

2. Department of Child, Youth and Family Studies, College of Education and Human Sciences, University of Nebraska-Lincoln, Lincoln, Nebraska, USA

3. Institute for Clinical and Translational Science, The University of Iowa, Iowa City, Iowa, USA

Corresponding author - Ibrahim H. Acar, Department of Early Childhood Education, Istanbul Medipol University, Room C-307, Kuzey Kampus, Beykoz, 34810 Istanbul, Turkey, email iacar@huskers.unl.edu

\begin{abstract}
The current study aimed to examine the associations between teacher presence and social scaffolding and preschool children's peer interactions. Using a time sampling method, peer interactions of 22 four- and five-year-old preschoolers (12 girls; Mage $=52.95$ months) and teacher behavior were observed on two different days during various classroom activities in seven public preschool classrooms. Eco-behavioral analyses revealed that (a) teacher presence was negatively associated with positive peer interactions; (b) teacher absence was positively associated with negative peer interactions; (c) positive change of peer interactions was more likely to occur when the teacher was present; (d) children showed more positive peer interactions during child-directed activities than during adult-directed activities or daily routines and transitions; and (e) teacher's social scaffolding was positively associated with children's positive peer interactions although it occurred only for $3.61 \%$ of the intervals during which the teacher was in close proximity to children. In addition, although the likelihood for children's positive interaction was over 2 times higher in child-directed activities in comparison to adult-directed activities, teacher presence still seems very important for inhibiting negative peer interactions.
\end{abstract}

Keywords: preschool children, peer interactions, teacher scaffolding, teacher presence, classroom contexts 


\section{Introduction}

Early childhood is an important period for individuals to establish first structures of social relationships and foundations for future development. Children's socialization in early childhood is a critical building block for their concurrent and future development (Eisenberg, Fabes, and Spinrad 2006; Rogoff 1990) and occurs through children's interactions with their teachers and peers while they participate in various activities (Bierman 2004; Pianta 1999).

In classroom settings, teachers are generally viewed as leaders of the social environment and facilitators for children's positive peer interactions (Farmer, McAuliffe Lines, and Hamm 2011). Teachers play a vital role in shaping the social ecology and learning environments by establishing and enforcing rules for peer interactions (Water and Bateman 2013), effectively managing challenging or negative interactions among children and intentionally scaffolding positive peer relationships and interactions (Farmer, McAuliffe Lines, and Hamm 2011). In addition, teachers use a variety of pedagogical strategies, such as helping children resolve interpersonal conflicts and promoting effective play engagement (Baker et al. 2009; Wentzel 2003). Teachers' positive relationships with children (e.g. close, sensitive, supportive) have been associated with children's positive peer interactions (Ladd 2005; Rudasill et al. 2013). Considering the importance of teachers' scaffolding for children's peer interactions, in this study, we investigated how teachers' presence and social scaffolding were related to children's peer interactions in various classroom contexts.

\section{Importance of teacher presence on peer interactions}

Teacher presence is an important contributor to children's positive peer interactions in preschool settings (Robson and Rowe 2012; Singer et al. 2014). In the current study, we operationalized teacher presence as teacher's physical proximity (i.e., within three feet) to the target child during peer interactions (Kontos 1999). This criterion allowed us to observe teachers' potential interactions with the children. Teachers' involvement and presence have been both positively and negatively associated with children's peer interactions (Kontos and Wilcox-Herzog 1997; Legendre and Munchenbach 2011). In one study, teachers' direct involvement in young children's peer interactions during free play was negatively related to their peer interaction (Kontos and Wilcox-Herzog 1997). In another study, older toddlers and young preschoolers were more likely to engage in peer interactions when the caregiver was not in proximity and chose the caregiver as a play partner over peers when the caregiver was available within close distance (Legendre and Munchenbach 2011). On the contrary, Dutch researchers examined teachers' interactions with children during play activities and found that, when teachers were engaged with the children by talking or reciprocally interacting with them, their presence was supportive for children's positive peer play engagement (Singer et al. 2014). More specifically, as teachers were consistently proximal to children, children exhibited higher-level play engagement with peers (Singer et al. 2014). On the other hand, when the teacher was present for a short time or walking around without interacting with children, children were less engaged in play activities. Harper and McCluskey (2003) also found that the teacher was more likely to engage a child in peer 
interactions when the child was not participating in social interactions, which might have shown as a negative association between teacher involvement in social interactions and children's social behaviors.

\section{Role of teacher scaffolding in peer interactions}

Children's socialization occurs within a social context where children interact with and are guided by social partners, such as parents, peers, and teachers (Rogoff 1990; Vygotsky 1978). The development and learning of a child can occur most effectively within his or her Zone of Proximal Development (ZPD), the zone between the child's current and potential levels of development (Vygotsky 1978). Modeling and scaffolding provided by adults and more competent peers within the ZPD help children solve interpersonal problems, learn new knowledge, and develop social skills, especially in the context of cooperative activities (i.e., guided participation) (Rogoff 1990). Through scaffolding, children learn to use intraand inter-personal skills (inner and social speech as described in Vygotsky's theory) as a mechanism for peer interactions. As Vygotsky (1978) posited, there is a dynamic interplay between mind and language that occurs through social interactions between a child and the environment in the ZPD. Investigating children's intermental (between child and social environment) processes may give us a better idea about how children develop social interactions in natural settings.

Consistent with the concept of the ZPD, teachers observe children's independent activities to support and scaffold their learning and development as needed not by correcting them but by guiding and teaching them (Farmer, McAuliffe Lines, and Hamm 2011; Hoa, Gol-Guven, and Bagnatoc 2012; Pianta 1999). From this perspective, teachers play an important role in scaffolding the cognitive and social development of children (Farmer, McAuliffe Lines, and Hamm 2011; Goble et al. 2016; Pianta 1999). In the current study, teacher's social scaffolding is defined as the support teachers provide within children's ZPD to assist their learning and development of new concepts and skills, and examples include teachers' modeling, participation, promoting communications among children, acknowledging and praising children's positive behaviors, and facilitating children's positive interactions.

Teachers' sensitive awareness of children's need as well as their physical proximity enhances children's peer acceptance and social interactions (Ainsworth et al. 1978; Mashburn et al. 2008). Teachers' observed emotional support (i.e., warm approach, emotional sensitivity, encouragement, and effective dealing with children's concerns during peer interactions) helped children display prosocial behaviors and behavioral self-control in firstgrade classrooms (Merritt et al. 2012). Teachers' behavior management skills and spontaneous support on the spot during peer interactions as scaffolding strategies also may help children demonstrate and develop positive peer interactions in early childhood (Farmer, McAuliffe Lines, and Hamm 2011). When a teacher sees two children in an interpersonal conflict, he/she may approach the children and guide them by defining the problem, helping the children come up with possible solutions to the problem, and facilitating the interpersonal problem-solving processes between the children (Kemple and Hartle 1997). 


\section{Early childhood classroom contexts and peer interactions}

The aforementioned findings suggest that teacher presence and social scaffolding play an important role in children's peer interactions. However, children's interactions with peers may also depend on type of activity (e.g., free choice, center) and nature of activity (e.g., child-managed, teacher-managed), and teachers' influence may also depend on the nature of activities and activity settings where children interact with one another (Goble et al. 2016; Kontos 1999; Kontos et al. 2002; Vitiello et al. 2012). Previous research found that children interacted with one another more frequently during child-directed activities such as free play and outdoor time (Fuligni et al. 2012; Vitiello et al. 2012). Further, children tended to show positive engagement with peers during child-directed activities (Vitiello et al. 2012). A more recent study by Goble et al. (2016) found that the effects of teacher behavior on children's social outcome varied depending on whether they interacted with children in child- managed or teacher-managed activities. This is also consistent with the notion of guided learning and participation where teachers should work with children within their ZPD by interacting and recognizing problems that children are not capable of solving by themselves (Vygotsky 1978).

Peer interactions enable children to develop social, cognitive, academic, and communication skills (Beilinson and Olswang 2003; Buhs and Ladd 2001; Guralnick et al. 2007; Ladd 2005). Peer interactions in early childhood refer to behavioral processes that happen verbally or nonverbally among friends or peer groups (Ladd 2005). The nature of peer interactions in early childhood can be positive where children demonstrate prosocial behaviors and empathy in their interactions. It can also be negative where children demonstrate hostile and aggressive behaviors during their interactions (Sebanc 2003). Children's peer interactions are influenced by many individual and environmental factors including parents, teachers, and classroom contexts (Gleason et al. 2005; Merritt et al. 2012). In the current study, we observed teacher presence and scaffolding and their association with children's peer interactions in various preschool classroom contexts to gain a better understanding of classroom dynamics.

\section{Language skills and parental education level}

A child's ability to initiate and maintain conversations with peers using language as a tool to express their emotions and opinions has been found to help children form positive peer interactions (McCabe 2005). Further, children's language skills have been associated with their interactions with peers (Qi, Kaiser, and Milan 2006). Overall, the previous research emphasizes the importance of children's language skills in entering peer interactions as well as communicating effectively with teachers (Gifford-Smith and Brownell 2003). In addition, familial risk factors also play a role in children's social interactions with peers (Ladd 2005). One of the most prominent familial risk factors is parental education level, and it tends to be negatively related to children's peer interactions in early childhood (Nagin and Tremblay 2001). In the analyses, we used these two as control variables. 


\section{The current study}

This study aimed to answer the following research questions using preschool classroom observation data: (1) How often is a teacher present during peer interactions and how often do they scaffold peer interactions? (2) Are teacher presence and teacher social scaffolding associated with children's positive peer interactions while the context and nature of activities are taken into account? (3) Are teacher presence and teacher social scaffolding associated with children's negative peer interactions while the context and nature of activities are taken into account? (4) Are teacher presence and teacher social scaffolding associated with the positive change of peer interactions?

\section{Method}

\section{Participants}

The data were collected in 2011 and 2012 from a midsized Midwestern city in the United States. Twenty-two four- and five-year-old preschool children (12 girls; mean age $=52.95$ months; range $=39$ to 61 months; $S D=6.10$ ) and their parents and teachers participated in the study. Children were enrolled in one of seven half-day preschool classrooms, and one to three children were in the same classroom. Parents were asked to voluntarily participate in the study, so the children were not randomly selected from each classroom. More than half of the children were European American $(n=12)$, followed by African American $(n=4)$, Asian/Asian American $(n=2)$, Hispanic/Latino $(n=1)$, and mixed $(n=2)$, and none of them had an identified disability or language delay when participating in this study. About $23 \%$ of parents had a Bachelor of Arts (BA)/Bachelor of Science (BS) or higher-level degree. The participating preschool classrooms were receiving funding from Head Start, Title I Preschool, and the state and serving many children from low-income families and about four to six children with at least one identified disability. The teachers in these classrooms had at least a BA/BS degree in early childhood education and 3-15 years of early childhood teaching experience. At least four adults were present in each classroom including a head teacher, a teacher aid or an assistant teacher, a special education teacher, and a student volunteer (e.g., practicum student) although the special education teacher was in the classroom to primarily work with children with disabilities on a one-on-one basis.

\section{Procedures}

The research protocols and the procedures of the current study were approved by the researchers' university's Institutional Review Board (IRB) before the participants were contacted for recruitment. The researchers sent an invitation to participate in the study to teachers of half-day public preschool classrooms. Upon the receipt of teacher permission, we recruited families enrolled in their classroom by sending recruitment packets containing a letter explaining the study, a parent questionnaire, and a parent informed consent form and asking parents to submit their signed consent form and completed questionnaire to their child's teacher in a sealed envelope. Three weeks after recruitment packets were distributed, researchers visited each classroom to pick up the completed documents from the teachers and scheduled visits for observations of classroom activities and interactions. 
Each child was asked to provide an assent before observations and assessment and notified that she or he could ask to stop at any time when feeling uncomfortable.

Using a time-sampling observational method, children and their teachers were observed in their classroom on two different days (i.e., once in fall 2011 and once in spring 2012) for the entire class hours except for the large group time. For each interval, the target child's behavior was observed for 20 seconds and then coded for 30 seconds during free play, small group, routines and transitions, and outdoor play times. The time-sampling method was based on previous research conducted for the same purpose (e.g., Early et al. 2010; Kontos 1999), and our piloting of different lengths of intervals showed that 20 seconds was long enough for peers to show salient interactions but short enough not to include too many different types of behaviors. We avoided observing children during circle time because it tends to be highly teacher-directed and structured with little room for spontaneous peer interactions. Teacher's social scaffolding behavior and talk were coded when the teacher was within three feet of the target child. The three-feet criterion was used to guarantee a clear opportunity for the teacher and children to interact with one another (Kontos 1999; Powell et al. 2008). Between the two observation time points, researchers assessed each child's expressive vocabulary, which took five minutes per child. Teachers were also asked to report their educational background and the number of years of their early childhood teaching experience. Once data collection was completed, the classrooms and the children received a collection of picture books.

\section{Measures}

Observation coding systems

We developed an observation coding system based on previous studies on the association between classroom contexts and children's and teachers' behavior and talk (Kontos 1999; Odom et al. 2000, 2006; Powell et al. 2008; Rubin 2001). For classroom contexts, categories included Context (e.g., indoor, outdoor) and Nature of Activity (e.g., adult-directed, childdirected). As for Nature of Activity, "child-directed" was coded when children make most choices and decisions related to the ongoing activity and materials to use (e.g., block play during free play time where children make decisions about what to build and how to build it; teachers could be a co-player) whereas "teacher-directed" was coded when the teacher was directing most parts of the ongoing activity by providing directions and explicit guidance (e.g., a small-group literacy activity where the teacher leads the activity while encouraging children to participate in the activity). For children's social behavior, categories included Type of Social Play (e.g., engaged with one peer) and Nature of Peer Interaction (e.g., asks questions, helps, expresses emotions). The codes for Type of Social Play were used to create a variable indicating whether or not the child was engaged with peers. Nature of Peer Interaction initially included multiple codes used only when the child was engaged with another child, such as "ask questions," "helps," "leads peers," "expresses emotions," and "refuses or ignores peer." Then they were composited into Positive Peer Interactions or Negative Peer Interactions. Positive Peer Interactions were coded when the target child exhibited social behaviors likely to enhance peer relationships (e.g., helps, expresses positive emotions) while Negative Peer Interactions were coded when he or she 
showed behavior likely to create tension, exclusion, or coercion among children (e.g., refuses or ignores peer). Teachers' social scaffolding behavior was also coded when a teacher was present within three feet of the target child (e.g., teaches/models, promotes communications, redirects, comments/suggests/questions, refers to a peer) (see Appendix). Teachers' scaffolding of other learning (e.g., literacy, math) was not coded since the primary focus of the current study was on teacher behaviors likely to enhance peer interactions.

Children's and teachers' behavior and classroom contexts were observed live using a 20 -second interval and then coded for 30 seconds. We decided to use 20-second intervals because 20-second intervals seemed to provide the proper amount of information regarding children's activities and social interactions and help coders reliably record the data. Each child was observed on two different days. The number of intervals during which each child was observed ranged from 172 to $353(M=266.14 ; S D=46.68)$.

Two graduate and one undergraduate research assistants were trained to use the coding system using four one-hour videotapes of interactions that contained a variety of classroom activities including indoor and outdoor free play, small group activities, meals, snacks, and transitions. Once we reached $85-100 \%$ agreements on all codes, we started the data collection. To maintain inter-coder reliability of at least $80 \%$ throughout the data collection, we met to check reliability every three weeks with two 20-minute videotapes with interactions from various contexts. We could not check the reliability in the setting where the actual data were collected because of the time constraints of the research assistants and also because these participating classrooms were already very crowded and teachers wanted to limit the number of adults present in the classroom at any one point in time. The advantage of using video clips taken at a university laboratory school was that we could select videos that included a variety of social interactions between a teacher and children so the coders could practice differentiating individual codes. When disagreements arose, we met to discuss and resolve the issues before resuming data collection. The average percent agreements ranged from $75 \%$ (i.e., Nature of Peer Interaction) to $100 \%$ (i.e., Context, Nature of Activity).

\section{Expressive vocabulary}

Children's expressive vocabulary was measured using the Woodcock-Johnson III Picture Vocabulary Test. The administrator asked the child to say the name of each picture presented by asking, "What is this?" or "What is this called?" It took five minutes for each child to complete the assessment. This variable was used as a child-level covariate, and $t$ score was used $(M=50 ; S D=10)$ in the analysis.

Parent questionnaire

Parents reported on their education level as well as their child's demographic information: age, sex, and ethnicity. A dichotomous variable was created for child's ethnicity, as the majority of the participating children were European American (1 = European American; $0=$ non-European American). Parent's educational level was categorized also into $1=$ $\mathrm{BA} / \mathrm{BS}$ or higher or $0=$ no BA/BS. Parent's educational level was included in the analyses as a child-level control variable due to its known association with children's overall developmental outcomes. 
Study variables

Using the frequency and the conceptual meaning of each code, we created composite variables to be entered in the main analyses. Codes for child's peer interactions were collapsed into two dichotomous variables on the basis of their conceptual congruence: Positive Peer Interaction (e.g., shows interest in peer, helps or receives help, expresses emotions) and Negative Peer Interaction (i.e., competes with peer, refuses or ignore peer). Codes for teacher behavior were combined to create two dichotomous variables: Teacher Presence (i.e., whether a teacher was present within three feet of the target child) and Teacher Social Scaffolding (e.g., promotes communications; comments, suggests, or questions). Due to low frequencies, teacher social scaffolding codes were collapsed into one dichotomous variable $(1=$ social scaffolding; $0=$ no social scaffolding). As for Context, Indoor (i.e., indoor classroom, indoor gym) versus Outdoor was used in the analyses. As for Nature of Activity, Childdirected, Teacher-directed, and Daily Routines and Transitions were used in the analyses.

\section{Results}

\section{Preliminary results}

The total data included 5855 intervals of observation (i.e., behavior-level) extracted from 22 children (i.e., child-level) enrolled in 7 preschool classrooms. Children's peer interactions occurred in about $41.96 \%$ of the intervals observed $(n=2457$ intervals). Contexts of the interactions included Indoor (85.82\%) and Outdoor (14.12\%), and the Nature of Activity included Child-directed (50.21\%), Teacher-directed (11.2\%), and Daily Routines and Transitions (38.6\%). Descriptive statistics, frequencies of study variables, and participants' demographic information are presented in Table 1.

\begin{tabular}{|c|c|c|c|c|}
\hline Variables & Freq. & $\%$ & Mean $(S D)$ & Range \\
\hline \multicolumn{5}{|l|}{ Interval-Level $(N=5855)$} \\
\hline C Positive Peer Interactions & 2597 & 44.36 & & \\
\hline C Negative Peer Interactions & 270 & 4.61 & & \\
\hline C Positive Change of Peer Interactions & 806 & 13.87 & & \\
\hline Teacher Presence & 3785 & 62.94 & & \\
\hline Teacher Social Scaffolding & 121 & 2.07 & & \\
\hline Context: Indoor (vs. Outdoor) & 5025 & 85.82 & & \\
\hline \multicolumn{5}{|l|}{ Context: Nature of Activity (missing $=5$ ) } \\
\hline Child-directed & 2937 & 50.21 & & \\
\hline Teacher-directed & 655 & 11.20 & & \\
\hline Daily Routines and Transitions & 2258 & 38.60 & & \\
\hline \multicolumn{5}{|l|}{ Child-Level $(N=22)$} \\
\hline C Age in Months & & & $52.95(6.10)$ & $39.00-61.00$ \\
\hline C Expressive Vocabulary Skills & & & $16.14(2.50)$ & $12.00-23.00$ \\
\hline C Gender (reference $=$ Male) & 10 & 45.45 & & \\
\hline C Ethnicity (reference $=\mathrm{EA})$ & 12 & 54.54 & & \\
\hline $\mathrm{P}$ Education (reference $=\mathrm{BA} / \mathrm{BS}$ or higher) & 5 & 22.73 & & \\
\hline
\end{tabular}

Notes: $\mathrm{T}=$ Teacher $\mathrm{C}=\mathrm{Child} ; \mathrm{P}=$ Parent; $\mathrm{EA}=$ European American 


\section{Frequencies of teacher presence and teacher social scaffolding}

To answer our first research question, we examined (a) the frequency and percentage of teacher presence out of the total number of observation intervals and (b) the ratio of teacher's social scaffolding behavior and talk to teacher presence. At least one teacher was present within three feet of the target child for $62.94 \%$ of the intervals observed (i.e., 3,685 intervals). When present, the teacher was using social scaffolding strategies for $3.61 \%$ of the intervals observed (i.e., 133 out of 3685 observations).

\section{Association between teacher presence and teacher social scaffolding and children's peer interactions}

To examine the association between teacher presence and teacher social scaffolding and children's positive peer interactions, a multilevel logistic regression analysis was used, given the hierarchical structure of our data where observations were nested within children (Bryk and Raudenbush 1992). The SAS Proc Glimmix was used for its flexibility in modeling a generalized linear mixed model (GLMM). The dependent variable was dichotomous (i.e., whether or not the target child interacted with at least one peer), and predictors included teacher presence (yes vs. no; first model only; Level 1), teacher social scaffolding (yes vs. no; second model only; Level 1), the context (i.e., indoor, outdoor; Level 1) and the nature (i.e., teacher-directed, child-directed, routines/transitions; Level 1) of activities, child's age in months, child's sex, child's ethnicity (European American vs. non-European American), child's expressive vocabulary skills, and parent education (BA/BS vs. less than BA/BS). We created two separate models (i.e., one with teacher presence and the other with teacher social scaffolding) because, for the second model, we could only include the observations that occurred when a teacher was present.

\section{Teacher presence, nature of activity, and children's positive peer interactions}

Results revealed that when no teacher was present the likelihood for children to show positive peer interaction was 2.86 times higher than when a teacher was present $(t(5246)=$ $13.69, p<.01)$. The likelihood for children to show positive peer interaction was 2.09 times higher in child-directed compared to adult-directed activities $(t(5246)=6.54, p<.01)$, and the likelihood for children to show positive peer interaction was still 3.32 and 1.59 times higher in child-directed and adult-directed activity when compared to daily routines and transitions $(t(5246)=15.1, p<.01$ and $t(5246)=4.35, p<.01$, respectively). The likelihood for positive peer interaction was 1.18 times higher when children's language score increased by 1 point $(t(5246)=2.37, p=.02$; see Table 2$)$. 


\begin{tabular}{|c|c|c|c|c|}
\hline & Estimates & $S E$ & Odds ratio & $p$ \\
\hline \multicolumn{5}{|l|}{ Fixed effects } \\
\hline Intercept & -1.66 & 1.70 & .19 & .34 \\
\hline Teacher Presence (reference $=$ Yes) & 1.05 & .08 & 2.86 & $<.01$ \\
\hline Indoor (reference $=$ Yes) & .06 & .10 & 1.06 & .51 \\
\hline \multicolumn{5}{|l|}{ Nature of Activity (reference = daily activity) } \\
\hline Child-directed & 1.20 & .08 & 3.32 & $<.01$ \\
\hline Adult-directed & .46 & .11 & 1.59 & $<.01$ \\
\hline C Sex $($ reference $=$ Male $)$ & .07 & .35 & 1.07 & .85 \\
\hline C Ethnicity $($ reference = EA) & .26 & .30 & 1.30 & .38 \\
\hline$P$ Education (reference $=\mathrm{BA} / \mathrm{BS}$ or higher) & .20 & .37 & 1.22 & .58 \\
\hline C Age & -.05 & .03 & .95 & .14 \\
\hline C Lang & .16 & .07 & 1.18 & .02 \\
\hline \multicolumn{5}{|l|}{ Random effect } \\
\hline Random intercept & .33 & .13 & & .01 \\
\hline \multicolumn{5}{|l|}{ Model fit } \\
\hline -2 Res log pseudo-likelihood & $23,874.13$ & & & \\
\hline
\end{tabular}

Notes: $\mathrm{T}=$ Teacher $\mathrm{C}=\mathrm{Child} ; \mathrm{P}=$ Parent; $\mathrm{EA}=$ European American; $\mathrm{SE}=$ Standard error

\section{Teacher presence, nature of activity, and children's negative peer interactions}

We examined the association between teacher presence, teacher social scaffolding, and children's negative peer interactions using the same statistical models to answer our third research question. We found that there was a greater likelihood for negative peer interactions to occur when no teacher was present than when a teacher was present $(t(5254)=$ $5.12, p<.0001)$. Specifically, when no teacher was present, the likelihood for children to show negative peer interaction was 2.38 times higher than when a teacher was present. In addition, the likelihood of negative peer interactions was 3.36 times higher in child-directed activities compared to daily routines and transitions $(t(5246)=5.37, p<.01)$. The likelihood for negative peer interactions to happen was 2.62 times higher when their parent did not have a BA/BS degree than when she or he did $(t(5246)=2.35, p=.02)$. Teacher social scaffolding was not associated with children's negative peer interactions (see Table 3 ). 


\begin{tabular}{lcccc}
\hline \multicolumn{6}{l}{ Table 3. Association between teacher presence and child's negative peer interactions } \\
\hline & Estimates & SE & Odds ratio & $p$ \\
\hline Fixed effects & & & & \\
$\quad$ Intercept & -8.99 & 2.02 & & .00 \\
Teacher Presence (reference = Yes) & .87 & .17 & 2.38 & $<.01$ \\
Indoor (reference = Yes) & -.05 & .17 & .95 & .76 \\
Nature of Activity (reference = daily activity) & & & 3.36 & $<.01$ \\
$\quad$ Child-directed & 1.21 & .23 & 1.22 & .57 \\
$\quad$ Adult-directed & .20 & .36 & .75 & .44 \\
C Sex (reference = Male) & -.29 & .38 & .97 & .93 \\
C Ethnicity (reference = EA) & -.03 & .32 & .02 \\
P Education (reference = BA/BS or higher) & .96 & .41 & 2.62 & .42 \\
C Age & .03 & .04 & 1.03 & .06 \\
C Lang & .14 & .07 & 1.15 & \\
Random effect & & & & \\
Random intercept & .30 & .17 & & \\
Model fit & & & & \\
-2 Res log pseudo-likelihood & $34,025.65$ & & & \\
\hline
\end{tabular}

Notes: $\mathrm{T}=$ Teacher; $\mathrm{C}=$ Child; $\mathrm{P}=$ Parent; $\mathrm{EA}=$ European American; $\mathrm{SE}=$ Standard error

Teacher presence, nature of activity, and positive change in children's peer interactions

An interval was coded as "positive change $=1$ (Yes)" if the child had not interacted with a peer at one interval but showed a peer interaction during the following observation interval; it was coded as "positive change $=0(\mathrm{No})$ " otherwise. Because there was no observation before the first observation interval for all children, it became the missing data. We used this "positive change" variable as our dependent variable in the analysis to answer our fourth research question. As shown in Table 5, when a teacher was present, there was a greater likelihood for children to change the nature of their peer interactions (i.e., change from no peer interaction or negative peer interaction to positive peer interaction) than when no teacher was present $(t(5214)=-5.05, p<.0001)$. Specifically, the likelihood for a positive change to occur was 1.56 times higher when a teacher was present than when she or he was not (see Table 4). 
Table 4. Association between teacher presence and positive change in peer interactions

\begin{tabular}{|c|c|c|c|c|}
\hline & Estimates & $S E$ & Odds ratio & $p$ \\
\hline \multicolumn{5}{|l|}{ Fixed effects } \\
\hline Intercept & -2.09 & .52 & & \\
\hline$T$ Presence $($ reference $=\mathrm{No})$ & .51 & .11 & 1.66 & $<.0001$ \\
\hline Indoor $($ reference $=\mathrm{No})$ & .0003 & .13 & 1 & .999 \\
\hline \multicolumn{5}{|l|}{ Nature of Activity (reference $=$ daily activity) } \\
\hline Child-directed & .06 & .10 & 1.06 & .57 \\
\hline Teacher-directed & -.18 & .14 & .84 & .19 \\
\hline C Age & .002 & .01 & 1 & .84 \\
\hline$C \operatorname{Sex}($ reference $=$ Male $)$ & .20 & .11 & 1.22 & .07 \\
\hline C Ethnicity (reference $=$ EA) & -.10 & .09 & .90 & .24 \\
\hline C Expressive Vocabulary & .009 & .02 & 1 & .67 \\
\hline$P$ Education (reference $=\mathrm{BA} / \mathrm{BS}$ or higher) & .11 & .12 & 1.11 & .37 \\
\hline \multicolumn{5}{|l|}{ Model fit } \\
\hline -2 Res log pseudo-likelihood & $26,155.67$ & & & \\
\hline
\end{tabular}

Notes: Random intercept was fixed to be 0 because of nonpositive $\mathrm{G}$ matrix. The reason might be due to a sparse positive change. $\mathrm{T}=$ Teacher $; \mathrm{C}=\mathrm{Child} ; \mathrm{P}=$ Parent; $\mathrm{EA}=$ European American; $\mathrm{SE}=$ Standard error

\section{Teacher social scaffolding, nature of activity, and children's positive peer interactions}

We conducted the same analysis using teacher's social scaffolding as an independent variable and found that the likelihood for children to show positive peer interaction was 13.83 times higher when a teacher provided social scaffolding than without teacher social scaffolding $(t(3279)=8.99, p<.01)$. In addition, the likelihoods for children to show positive peer interactions were 2.90 and 1.39 times higher in child-directed and teacher-directed activities compared to daily routines and transitions $(t(3279)=11.13, p<.01$ and $t(3279)=$ $2.87, p<.01$, respectively); and 1.13 times higher when children's language score increased by $1(t(3279)=2.1, p=.04$; see Table 5$)$. 


\begin{tabular}{lcccc} 
Table 5. Association between teacher social scaffolding and child's positive peer interactions \\
\hline & Estimates & SE & Odds ratio & $p$ \\
\hline Fixed effects & & & & \\
Intercept & .72 & 1.45 & 2.05 & .63 \\
Teacher social scaffolding (reference = No) & 2.63 & .29 & 13.83 & $<.01$ \\
Indoor (reference = Yes) & .01 & .16 & 1.01 & .97 \\
Nature of Activity (reference = daily activity) & & & & \\
$\quad$ Child-directed & 1.06 & .10 & 2.90 & $<.01$ \\
Adult-directed & .33 & .11 & 1.39 & .00 \\
C Sex (reference = Male) & .12 & .30 & 1.13 & .68 \\
C Ethnicity (reference = EA) & .13 & .25 & 1.13 & .61 \\
P Education (reference = BA/BS or higher) & .25 & .31 & 1.28 & .43 \\
C Age & -.03 & .03 & .97 & .26 \\
C Lang & .12 & .06 & 1.13 & .04 \\
Random effect & & & & \\
Random intercept & .21 & .10 & & \\
Model fit & & & & \\
-2 Res log pseudo-likelihood & $15,059.8$ & & & \\
\hline
\end{tabular}

Notes: $\mathrm{T}=$ Teacher $\mathrm{C}=\mathrm{Child} ; \mathrm{P}=$ Parent; $\mathrm{EA}=$ European American; $\mathrm{SE}=$ Standard error

\section{Discussion}

In the current study, we examined the associations among teacher presence, teacher social scaffolding, and children's peer interactions; and how children's peer interactions varied across classroom contexts. Three main findings emerged. First, teacher presence was negatively associated with positive peer interactions but positively associated with positive change in the nature of children's peer interactions. Second, the likelihood for children's positive peer interactions was significantly higher during child-directed activities in comparison with adult-directed activities or transitions and routines. Third, teachers' social scaffolding was positively associated with children's peer interactions. Unique contributions of the current study are that observing children in different settings provided detailed contextual information related to peer-peer and teacher-child interactions; and that we examined the association between teacher presence and the positive change of children's peer interactions, which enabled us to better understand the role of teacher presence in children's peer interactions.

\section{Teacher presence and peer interactions}

Teacher presence is considered as an important contributor to children's development in early childhood classrooms; however, its association with children's peer interactions has yielded conflicting findings. In the current study, children were found to exhibit positive peer interactions less frequently when a teacher was in proximity to them. This finding is contradictory to the findings from previous studies that teacher presence was positively associated with children's positive peer interactions (e.g., Singer et al. 2014) but consistent with the negative associations others found between teacher involvement and children's 
engagement with peers (e.g., Goble et al. 2016; Legendre and Munchenbach 2011). Considering the correlational nature of our analyses, it is possible to interpret the negative association between teacher presence and positive peer interactions as indicating that teachers may not feel it necessary to be in proximity to children when children are already exhibiting positive peer interactions. We also found a negative association between teacher presence and negative peer interactions, which may indicate that teacher presence might have at least prevented negative peer interactions from happening. In addition, the significant link between teacher presence and the positive change in children's peer interactions adds to the aforementioned speculation that teacher presence might have positively contributed to children's peer interactions in a way that changes the nature of interactions to the positive direction (i.e., changes from no interactions to interactions or from negative to positive interactions). These findings about teacher presence are, to some degree, aligned with the findings of Harper and McCluskey (2003) where the negative association between teacher involvement and children's peer interactions was explained by examining the sequence of events. It may be possible that teachers tend not to intervene or stay close to children while children are actively and positively interacting with peers but predict the change in the nature of peer interactions when negative or no peer interactions occur and thus inhibit negative peer interactions. The negative association between teacher-directed activities and teacher-reported academic and social skills of young children found in Goble et al. (2016) also provides additional evidence that teachers may tend to become more involved with those who need more support in both academic and social skills probably by providing more teacher-directed activities.

Our model included the nature of activity while testing the effect of teacher presence on children's peer interactions. The findings revealed that, while a teacher was present, children positively interacted with peers more frequently during child-directed or teacherdirected activities compared with daily routines and transitions. In addition, the likelihood for children's positive interactions was over two times higher in child-directed activities in comparison with adult-directed activities. A similar pattern was also found in the model where we examined the association between teacher social scaffolding and positive peer interactions. This adds more specific information to previous conceptualization of ecological studies of the behavior-environment association (Li 1984) whereby children interacted with one another differently in different school contexts (Booren, Downer, and Vitiello 2012; Feldman and Matos 2013). For example, four- or five-year-old children in unstructured, child-directed settings were engaged in cooperative and communicative interactions with peers more frequently than in structured, adult-directed activities (Ramani 2012). Children appeared to interact with one another more frequently and positively when they were free to explore and communicate with peers (Rubin, Bukowski, and Parker 2006). These findings may indicate that positive peer interactions are more likely to occur when children are provided with self-directed activities but with some level of teacher presence to prevent negative peer interactions from occurring. This interpretation seems fairly plausible in that a recent study revealed a positive association between teacher-child conversation within child-managed contexts and teacher-reported social skills (Goble et al. 
2016). It would be interesting to further investigate how different combinations of the nature and the types of teacher-child interactions contribute to children's peer interactions and how different types of peer interactions elicit different teacher behaviors.

Although our findings suggest that child-directed activities be a good context for positive peer interactions, adult-directed activities might still be a better context for positive peer interactions when compared with daily routines and transitions (i.e., child-directed $>$ adult-directed $>$ daily routines and transitions). This may imply that, for young children to exhibit positive peer interactions, they may need either a specific activity or task to focus on and/or ample time to develop the interactions, which daily routines and transitions may not provide. The lack of positive interactions during daily routines and transitions is consistent with the findings of Vitiello et al. (2012).

\section{Teacher social scaffolding and peer interactions}

Preschool teachers tend to stay close to children for about $70-80 \%$ of time in the classroom (Wilcox-Herzog and Kontos 1998), as the current study also found. However, this may not mean that the teachers engage children in social communications or peer interactions for the entire time. According to our data, teachers were intentionally scaffolding children's peer interactions for $3.61 \%$ of the time when they were in close proximity to the children. This lack of teachers' social scaffolding should not be understood to mean that teachers were not engaging children in any kinds of social interactions. The current study focused only on teachers' scaffolding behavior promoting peer interactions, so the behaviors scaffolding children's learning in other areas (e.g., literacy development) were intentionally not recorded. Teachers might have been engaging children in other areas of learning for the majority of time when they were close to the target child. The literature has also showed that teachers actively engage children during large group activities more frequently than during recess and free choice activities (Booren, Downer, and Vitiello 2012; Fuligni et al. 2012; Vitiello et al. 2012). In addition, teachers might have been more engaged with children participating in task-oriented activities or with those who needed more individualized one-on-one support and thus may not have been engaging children in peer interactions more explicitly. In a recent study, children were engaged in whole group activities for $50 \%$ of their preschool class time (Powell et al. 2008) where they were engaged in positive interactions with their teacher. It is fairly possible that teachers were intentionally not as much engaged in children's social interactions while they were not leading the activities. Researchers have called it "an early childhood error" when early childhood teachers provide children with developmentally appropriate materials and environment without providing further guidance and responsive interactions while they are engaged in play (Bredekamp and Rosegrant 1992, 3; Kontos 1999). Although our finding may not exactly represent the early childhood error, it provides good implications for practice in promoting young children's social interactions and peer relationships.

Another finding of the current study was that teacher social scaffolding, when it occurred, was associated with children's positive peer interactions. This finding is aligned with the conceptualization that the teacher can be seen as a leader guiding children's positive behaviors with peers (Farmer, McAuliffe Lines, and Hamm 2011) and that the scaf- 
folding provided by adults promotes children's learning (Vygotsky 1978). Previous research also showed that children were engaged in fewer interpersonal conflicts with peers during teacher-directed activities than during free choice, recess, and routine/transition times (Booren, Downer, and Vitiello 2012).

In summary, the role of teachers in early childhood classrooms seems important in building children's social competence. Our findings show that young children are more likely to show positive peer interactions during child-directed activities; however, some level of teacher presence is likely to inhibit negative peer interactions, and teachers' social scaffolding may add more positivity to the context of peer interactions.

\section{Implications for practice and future directions}

The findings from the current study highlight the importance of teacher support (i.e., teacher presence and teacher social scaffolding) for children's peer interactions. These findings provides a research-based ground for the development of pedagogical practices and strategies that teachers can use in indoor and outdoor activities to improve children's positive peer interactions. Teachers can scaffold children's positive peer interactions by providing a nurturing environment, teaching social skills during teacher-directed play activities, or prompting and reinforcing positive interactions among children (Center on the Social and Emotional Foundations for Early Learning 2007; Farmer, McAuliffe Lines, and Hamm 2011). Our findings also can inform teacher-training programs about the importance of teachers' scaffolding of children's positive peer interactions and provide teachers with information regarding classroom contexts where positive peer interactions are more likely to occur. Furthermore, the finding about teacher presence possibly preventing negative peer interactions from occurring also informs that being in close proximity to children but not being intrusive of their interactions may be an effective strategy to promote positive peer interactions.

While this study provided a rigorous examination of teachers' contribution to children's peer interactions, it also helped us expand our ideas regarding next steps. In the current study, we did not have enough data to examine specific roles that teacher social scaffolding plays in sustaining or changing the nature of peer interactions although it is an important empirical question. It would be worthwhile to focus on specific teacher social scaffolding strategies included in this study to examine their effects on children's peer interactions in various contexts. Similarly, we did not examine specifically how children responded to teachers' scaffolding during peer interaction but rather focused on the change in the nature of children's social behaviors as an antecedent of teachers' scaffolding. A future study could examine specific dyadic or even triadic interactions between teachers and one or more children to examine on-the-spot responses of children to teachers' stimuli in social contexts and how those interactions become sustained. We were able to include interval/observation-level and child-level variables in our analyses with few variables at the teacher/classroom-level. Recent studies found classrooms' social and emotional climate to be an important factor predicting children's peer interactions and social-emotional outcomes (Booren, Downer, and Vitiello 2012; Howes 2011). A larger sample with more children in each classroom would enable us to meaningfully examine the associations among classroom factors, teacher behavior, and children's interactions. A follow-up study with a 
more qualitative focus would help us bring out individual cases to examine the consistency of peer interactions over time, specific positive and negative interactions varying by context, and a more in-depth understanding of the sequence of teacher behavior, child behavior, and contextual characteristics. Another suggestion for future research is that similar studies be conducted in settings where fewer teachers serve a group of young children (cf. on average, four teachers were present in the current study) to examine whether similar patterns of interactions between teachers and children occur.

Disclosure statement - No potential conflict of interest was reported by the authors.

\section{References}

Ainsworth, M. D., M. C. Blehar, E. Waters, and S. N. Wall. 1978. Patterns of Attachment: A Psychological Study of the Strange Situation. Hillsdale, NJ: Erlbaum.

Baker, J. A., T. P. Clark, A. Crowl, and J. S. Carlson. 2009. “The Influence of Authoritative Teaching on Children's School Adjustment: Are Children with Behavioural Problems Differentially Affected?" School Psychology International 30: 374-382.

Beilinson, J., and L. Olswang. 2003. "Facilitating Peer Group Entry in Kindergarteners with Deficits in Social Communication." Language, Speech, Hearing Services in Schools 34: 154-166.

Bierman, K. L. 2004. Peer Rejection: Developmental Processes and Intervention Strategies. New York: Guilford Press.

Booren, L. M., J. T. Downer, and V. E. Vitiello. 2012. “Observations of Children's Interactions with Teachers, Peers, and Tasks Across Preschool Classroom Activity Settings." Early Education and Development 23: 517-538. doi:10.1080/10409289.2010.548767.

Bredekamp, S., and T. Rosegrant. 1992. Reaching Potentials: Appropriate Curriculum and Assessment for Young Children. Vol. 1. Washington, DC: National Association for the Education of Young Children.

Bryk, A. S., and S. W. Raudenbush. 1992. Hierarchical Linear Models in Social and Behavioral Research: Applications and Data Analysis Methods. 1st ed. Newbury Park, CA: Sage Publications.

Buhs, E. S., and G. W. Ladd. 2001. "Peer Rejection as an Antecedent of Young Children's School Adjustment: An Examination of Mediating Processes." Developmental Psychology 37: 550-560.

Center on the Social and Emotional Foundations for Early Learning. 2007. Using Classroom Activities and Routines as Opportunities to Support Peer Interaction. http://csefel.vanderbilt.edu/kits/wwbtk5.pdf.

Diamond, K., S.-Y. Hong, and A. E. Baroody. 2008a. "Early Childhood Curricular Approaches to Promote Young Children's Social Competence." In Social Competence of Young Children: Risk, Disability, and Intervention, edited by W. H. Brown, S. Odom, and S. R. McConnell, 2nd ed., 165-184. Baltimore: Paul H. Brookes.

Early, D. M., I. U. Iruka, S. Ritchie, O. A. Barbarin, D-M. C. Winn, G. M. Crawford, P. M. Frome et al. 2010. "How Do Pre-kindergarteners Spend Their Time? Gender, Ethnicity, and Income as Predictors of Experiences in Pre-kindergarten Classrooms." Early Childhood Research Quarterly 25(2): 177-193. doi:10.1016/j.ecresq.2009.10.003.

Eisenberg, N., R. A. Fabes, and T. L. Spinrad. 2006. "Prosocial Development." In Handbook of Child Psychology: Social, Emotional, and Personality Development, edited by N. Eisenberg (Vol. Ed.), W. Damon, and R. M. Lerner (Series Eds.), Vol. 3, 646-718. New York: Wiley.

Farmer, T. W., M. McAuliffe Lines, and J. V. Hamm. 2011. “Revealing the Invisible Hand: The Role of Teachers in Children's Peer Experiences." Journal of Applied Developmental Psychology 32: 247-256. 
Feldman, E. K., and R. Matos. 2013. “Training Paraprofessionals to Facilitate Social Interactions between Children with Autism and their Typically Developing Peers." Journal of Positive Behavior Interventions 15: 169-179. doi:10.1177/1098300712457421.

Fuligni, A. S., C. Howes, Y. Huang, S. S. Hong, and S. Lara-Cinisomo. 2012. “Activity Settings and Daily Routines in Preschool Classrooms: Diverse Experiences in Early Learning Settings for Lowincome Children." Early Childhood Research Quarterly 27(2): 198-209. doi:10.1016/j.ecresq.2011 .10 .001 .

Gifford-Smith, M. E., and C. A. Brownell. 2003. "Childhood Peer Relationships: Social Acceptance, Friendships, and Peer Networks." Journal of School Psychology 41: 235-284.

Gleason, T. R., A. L. Gower, L. M. Hohmann, and T. C. Gleason. 2005. “Temperament and Friendship in Preschool-aged Children." International Journal of Behavioral Development 29(4): 336-344. doi:10.1080/ 01650250544000116.

Goble, P., L. D. Hanish, C. Lynn Martin, N. D. Eggum-Wilkens, S. A. Foster, and R. A. Fabes. 2016. "Preschool Contexts and Teacher Interactions: Relations with School Readiness." Early Education and Development 27(5): 623-641.

Guralnick, M. J., B. Neville, M. A. Hammond, and R. T. Connor. 2007. "The Friendships of Young Children with Developmental Delays: A Longitudinal Analysis." Journal of Applied Developmental Psychology 28: 64-79.

Harper, L. W., and K. S. McCluskey. 2003. "Teacher-child and Child-child Interactions in Inclusive Preschool Settings: Do Adults Inhibit Peer Interactions?" Early Childhood Research Quarterly 18: 163-184.

Hoa, H., M. Gol-Guven, and S. J. Bagnatoc. 2012. "Classroom Observations of Teacher-Child Relationships among Racially Symmetrical and Racially Asymmetrical Teacher-Child Dyads." European Early Childhood Education Research Journal 20 (3): 329-349. doi:10.1080/1350293X.2012.704759.

Howes, C. 2011. "A Model for Studying Socialization in Early Childhood Education and Care Settings." In Peer Relationships in Early Childhood Education and Care, edited by M. Kernan and E. Singer, 15-26. New York: Routledge.

Kemple, K. M., and L. Hartle. 1997. “Getting Along: How Teachers Can Support Children's Peer Relationships." Early Childhood Education Journal 24(3): 139-146.

Kontos, S. 1999. "Preschool Teachers' Talk, Roles, and Activity Settings During Free Play." Early Childhood Research Quarterly 14: 363-382.

Kontos, S., M. Burchinal, C. Howes, S. Wisseh, and E. Galinsky. 2002. “An Eco-behavioral Approach to Examining the Contextual Effects of Early Childhood Classrooms." Early Childhood Research Quarterly 17: 239-258.

Kontos, S., and A. Wilcox-Herzog. 1997. "Influences on the Competence of Children's Play with Objects and Peers in Early Childhood Classrooms." Early Childhood Research Quarterly 12: 247-262.

Ladd, G. W. 2005. Children's Peer Relations and Social Competence: A Century of Progress. New Haven, CT: Yale University Press.

Legendre, A., and D. Munchenbach. 2011. "Two- to Three-year-old Children's Interactions with Peers in Child-care Centers: Effects of Spatial Distance of Caregivers." Infant Behavior \& Development 34: 111-125. doi:10.1016/j.infbeh.2010.10.004.

Li, A. K. F. 1984. "Peer Interaction and Activity Setting in a High-density Preschool Environment." Journal of Psychology 116 (1): 45-54.

Mashburn, A. J., R. C. Pianta, B. K. Hamre, J. T. Downer, O. A. Barbarin, D. Bryant, Margaret Burchinal, and Diane M. Early. 2008. "Measures of Classroom Quality in Prekindergarten and Children's Development of Academic, Language, and Social Skills." Child Development 79: 732-749. 
McCabe, P. C. 2005. "Social and Behavioral Correlates of Preschoolers with Specific Language Impairment." Psychology in the Schools 41: 337-387.

Merritt, E. G., S. B. Wanless, S. E. Rimm-Kauffman, C. Cameron, and J. L. Peugh. 2012. “The Contribution of Teachers: Emotional Support to Children's Social Behaviors and Self-regulatory Skills in First Grade." School Psychology Review 40 (2): 141-159.

Nagin, D. S., and R. E. Tremblay. 2001. "Parental and Early Childhood Predictors of Persistent Physical Aggression in Boys from Kindergarten to High School." Archive of Genetic Psychiatry 58 (4): 389-394. doi:10.1001/archpsyc.58.4.389.

Odom, S. L., P. C. Favazza, W. H. Brown, and E. M. Horn. 2000. “Approaches to Understanding the Ecology of Early Childhood Environments for Children with Disabilities." In Behavioral Observation: Technology and Applications in Developmental Disabilities, edited by F. Symons, 193-214. Baltimore: Brookes.

Odom, S. L., C. Zercher, S. Li, J. M. Marquart, S. Sandall, and W. H. Brown. 2006. “Social Acceptance and Rejection of Preschool Children with Disabilities: A Mixed-method Analysis." Journal of Educational Psychology, 98: 807-823. doi:10.1037/0022-0663.98.4.807.

Pianta, R. C. 1999. Enhancing Relationships between Children and Teachers. Washington, DC: American Psychological Association.

Powell, D. R., M. R. Burchinal, N. File, and S. Kontos. 2008. "An Eco-behavioral Analysis of Children's Engagement in Urban Public School Preschool Classrooms." Early Childhood Research Quarterly 23: 108-123. doi:10.1016/j.ecresq.2007.04.001.

Qi, H. C., A. P. Kaiser, and S. Milan. 2006. “Children's Behavior During Teacher-directed and Childdirected Activities in Head Start." Journal of Early Intervention 28 (2): 97-110.

Ramani, G. B. 2012. “Influence of a Playful, Child-directed Context on Preschool Children's Peer Cooperation." Merrill-Palmer Quarterly 58 (2): 159-190.

Robson, S., and V. Rowe. 2012. “Observing Young Children's Creative Thinking: Engagement, Involvement and Persistence." International Journal of Early Years Education 20 (4): 349-364. doi:10.1080/ 09669760.2012 .743098$.

Rogoff, B. 1990. Apprenticeship in Thinking: Cognitive Development in Social Context. New York: Oxford University Press.

Rubin, K. H. 2001. The Play Observation Scale. College Park, MD: The Center for Children, Relationships and Culture, University of Maryland.

Rubin, K. H., W. M. Bukowski, and J. G. Parker. 2006. “Peer Interactions, Relationships, and Groups.” In Handbook of Child Psychology: Social, Emotional, and Personality Development, edited by N. Eisenberg, W. Damon, and R. M. Lerner, 571-645. Hoboken, NJ: John Wiley.

Rudasill, K., K. Niehaus, E. Buhs, and J. M. White. 2013. “Temperament in Early Childhood and Peer Interactions in Third Grade: The Role of Teacher-Child Relationships in Early Elementary Grades." Journal of School Psychology 51: 701-716. doi:10.1016/j.jsp.2013.08.002.

Singer, E., M. Nederend, L. Penninx, M. Tajik, and J. Boom. 2014. “The Teacher's Role in Supporting Young Children's Level of Play Engagement." Early Child Development \& Care 184 (8): 1233-1249. doi:10.1080/03004430.2013.862530.

Sebanc, A. M. 2003. “The Friendship Features of Preschool Children: Links with Prosocial Behavior and Aggression." Social Development 12 (2): 249-268. doi:10.1111/1467-9507.00232.

Vitiello, V. E., L. M. Booren, J. T. Downer, and A. P. Williford. 2012. "Variation in Children's Classroom Engagement Throughout a Day in Preschool: Relations to Classroom and Child Factors." Early Childhood Research Quarterly 27 (2): 210-220. doi:10.1016/j.ecresq.2011.08.005. 
ACAR, HONG, AND Wu, EUROPEAN EARLy CHILDHOOD EDUCATION RESEARCH JOURNAL 25 (2017)

Vygotsky, L. S. 1978. Mind in Society: The Development of Higher Psychological Processes. Cambridge, MA: Harvard University Press.

Water, J., and A. Bateman. 2013. "Revealing the Interactional Features of Learning and Teaching Moments in Outdoor Activity." European Early Childhood Education Research Journal 23 (2): 264-276.

Wentzel, K. R. 2003. “Motivating Students to Behave in Socially Competent Ways.” Theory Into Practice 42: 319-326.

Wilcox-Herzog, A., and S. Kontos. 1998. “The Nature of Teacher Talk in Early Childhood Classrooms and its Relationship to Children's Competence with Objects and Peers." Journal of Genetic Psychology 159: 30-44. 


\begin{tabular}{|c|c|c|}
\hline Code categories & Definition & Composites \\
\hline \multicolumn{3}{|l|}{ Context } \\
\hline Indoor classroom & $\mathrm{C}$ is in his/her classroom. & Indoor \\
\hline Indoor gym & $\mathrm{C}$ is in an indoor gym. & \\
\hline Outdoor classroom & $\mathrm{C}$ is in the program/center's outdoor classroom. & Outdoor \\
\hline \multicolumn{3}{|l|}{ Nature of Activity } \\
\hline Child-directed & $\begin{array}{l}\text { Teacher provides materials and environment, but } C \text { makes most } \\
\text { (or all) choices and decisions regarding the activity and what } \\
\text { materials to use. }\end{array}$ & Child-directed \\
\hline Teacher-directed & $\begin{array}{l}\text { Teacher seems to have clear goals and steps, which he/she is us- } \\
\text { ing to direct/structure the activity. Teacher provides materials } \\
\text { for the activity and gives directions and explicit guidance. }\end{array}$ & Teacher-directed \\
\hline $\begin{array}{l}\text { Daily routines/ } \\
\text { transitions }\end{array}$ & $\begin{array}{l}\text { C is involved in self-care, self-help, or transitions from one ac- } \\
\text { tivity to another. }\end{array}$ & $\begin{array}{l}\text { Daily routines/ } \\
\text { transitions }\end{array}$ \\
\hline \multicolumn{3}{|c|}{ Nature of Peer Interaction } \\
\hline $\begin{array}{l}\text { Simple } \\
\text { acknowledgment }\end{array}$ & $\begin{array}{l}\text { C provides or receives simple acknowledgments; supports } \\
\text { peers' statement; gains attention of peer; shows pride to peer. }\end{array}$ & $\begin{array}{l}\text { Positive Peer } \\
\text { Interactions }\end{array}$ \\
\hline $\begin{array}{l}\text { Shows interests } \\
\text { in peer }\end{array}$ & $\begin{array}{l}\text { C imitates a peer's verbalization or action; physically follows a } \\
\text { peer; or shows interest in what the peer does; initial stage of en- } \\
\text { gagement. }\end{array}$ & \\
\hline $\begin{array}{l}\text { Joins and/or invites } \\
\text { peer }\end{array}$ & $\begin{array}{l}\mathrm{C} \text { joins peer (who is alone) in a specific activity or invites peer to } \\
\text { an activity; beginning/initial stage of play. }\end{array}$ & \\
\hline $\begin{array}{l}\text { Asks simple } \\
\text { questions }\end{array}$ & $\begin{array}{l}\text { C asks a question to another peer; the question should not be a } \\
\text { help seeking question. }\end{array}$ & \\
\hline Describes & $\begin{array}{l}\mathrm{C} \text { describes what s/he sees, hears, wants, needs, and/or does; } \\
\text { pointing to what he needs or wants can be a nonverbal descrip- } \\
\text { tion of his needs/wants. }\end{array}$ & \\
\hline Actively engaged & $\begin{array}{l}\mathrm{C} \text { is actively engaged with peer(s) with or without play materi- } \\
\text { als; neither party is leading or being led; neither party is helping } \\
\text { or being helped; children are equally engaged in an activity or } \\
\text { an interaction. }\end{array}$ & \\
\hline Helps (active) & $\begin{array}{l}\text { C provides explanation and/or information for a peer; provides } \\
\text { help to a peer; offers help or shares materials that she/he was } \\
\text { using; models behavior; or indirectly helps peer accomplish or } \\
\text { complete a task. }\end{array}$ & \\
\hline $\begin{array}{r}\text { Seek or receives } \\
\text { help (passive) }\end{array}$ & $\begin{array}{l}\mathrm{C} \text { seeks or receives explanation and/or information from a peer; } \\
\text { requests or receives help from the peer. }\end{array}$ & \\
\hline Leads peer (active) & $\mathrm{C}$ is leading a peer in an activity. & \\
\hline $\begin{array}{l}\text { Is led by peer } \\
\text { (passive) }\end{array}$ & $\mathrm{C}$ is being led by a peer in an activity. & \\
\hline Expresses emotions & $\mathrm{C}$ is expressing emotions. & \\
\hline $\begin{array}{l}\text { Follows the (game) } \\
\text { rule }\end{array}$ & $\mathrm{C}$ follows classroom rules; $\mathrm{C}$ follows the rule of the group game. & \\
\hline
\end{tabular}
rule 


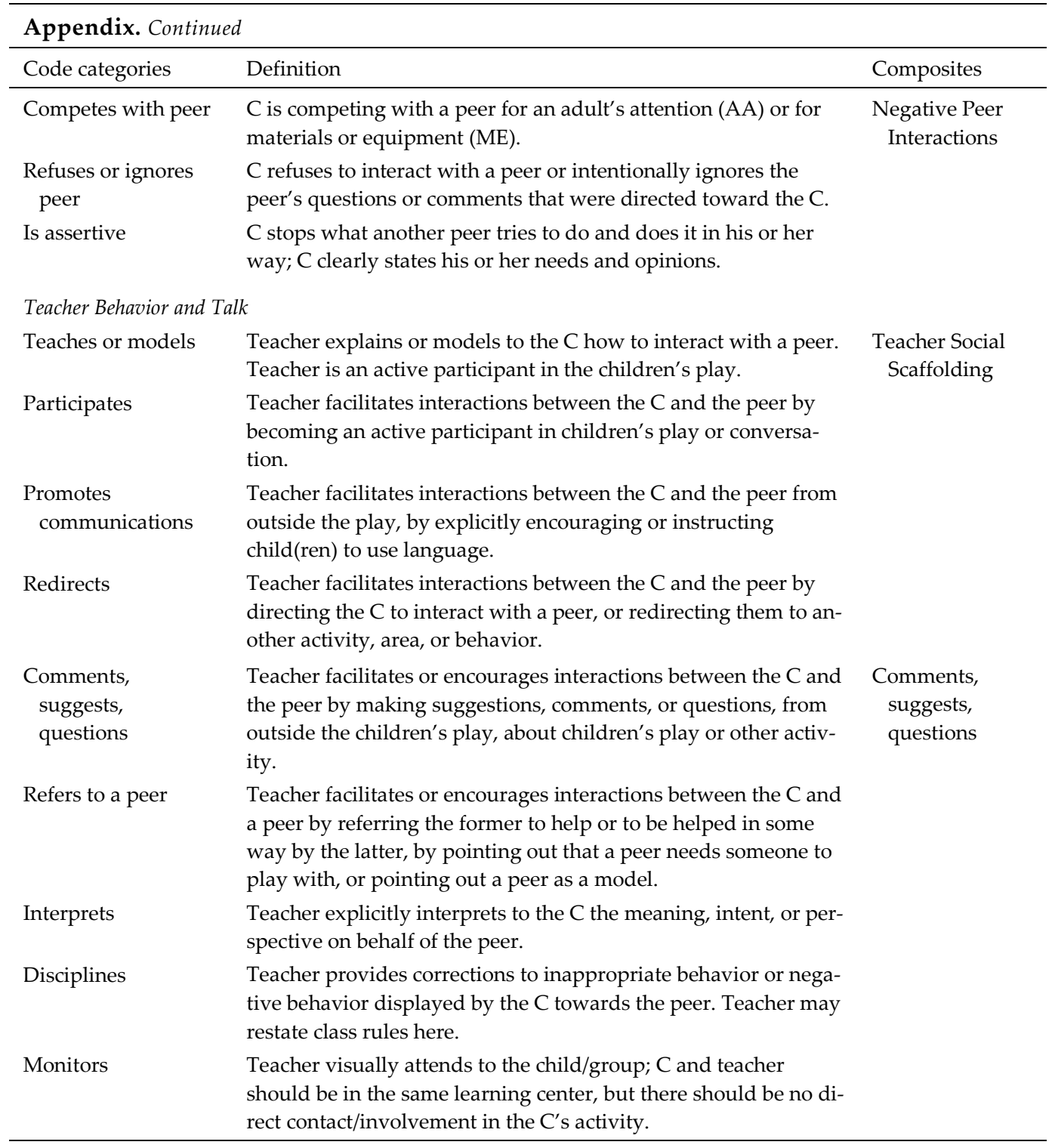

Notes: $\mathrm{C}=\mathrm{Child}$ (target child); $\mathrm{T}=$ Teacher 